\title{
Room temperature phosphorescence in cyclodextrins. Analytical applications
}

\author{
A. Muñoz de la Peña*, M.C. Mahedero and A. Bautista Sánchez \\ Department of Analytical Chemistry, University of Extremadura, 06071, Badajoz, Spain
}

\begin{abstract}
At room temperature, it is usually very difficult to observe phosphorescence emission of compounds in fluid solutions. The reported methods for the obtention of phosphorescence at room temperature in solution, generally imply an organization of the reagents at the microscopic level. The term "organized media" defines a category of molecules, which arrange, in solution, at the molecular level to form aggregates, whose microscopic properties are different from the properties of the bulk solvent.
\end{abstract}

quenching by dissolved molecular oxygen, a characteristic previously not observed in fluid solution at ambient temperature.

Cyclodextrins are composed of D-glucose residues joined by $\alpha(1 \rightarrow 4)$ linkages. $\alpha$-, $\beta$ - and $\gamma$-CDs, which are made up of six, seven and eight D-glucose residues, are the most common members of a CD family. These CDs are shaped like a truncated cone with a hollow, hydrophobic cavity in which a hydrophobic guest can be incorporated.

Molecular encapsulation by means of molecular inclusion complex formation offers a new approach in analytical chemistry. Generally, the inclusion complex involves the spatial entrapment of a single guest molecule in the cavity of the host molecule, without the formation of any covalent bonds. Cyclodextrins, cyclic non-reducing oligosaccharides, have been extensively used to obtain these inclusion complexes. In particular, many studies have focused on the ability of CDs to include guests of varying sizes in different stoichiometric ratios and several analytical applications of these complexes have been reported [15-30].

It is well documented that, depending upon the host CD (i.e. $\alpha-\beta$ - or $\gamma$-CD) and the size of the guest, different

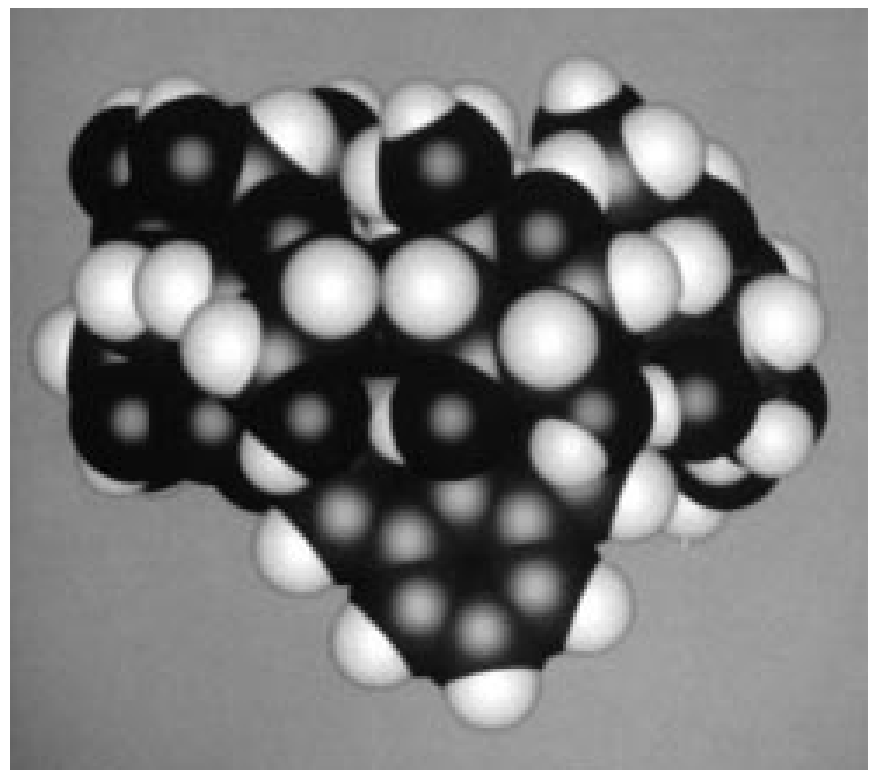

Figure 1. CPK model for the inclusion of pyrene in $\beta$-CD. Side view showing only part of the pyrene inside the $\beta-C D$ cavity. 
host/guest stoichiometries are possible. As an example, figure 1 shows the Corey-Pauling-Kolton (CPK) space-filling model for the inclusion of pyrene in $\beta$-CD. On the basis of molecular size, it is apparent that pyrene ( $8.2 \AA$ wide and $10.4 \AA$ long) is too bulky to fit entirely in the cyclodextrin cavity (7.8 $\AA$ ). Because of that, only part of the pyrene actually enters the $\mathrm{CD}$, being noticed that the internal diameter of $\beta$-CD severely limits the ability of pyrene to totally enter the cavity. Since approximately half of pyrene is located in the cavity, it was inferred that the other half (outside the cavity) is equally amenable to complex formation with another $\beta$-CD. In consequence, a 2:1 $\beta$-CD:pyrene stoichiometry is obtained [31].

A consequence of the rigidity of cyclodextrin conformation is that the guest is generally disordered when it does not fill the cavity, the Van der Waals forces being too loose. Indeed, the strength of interactions varies with the shape of the guest. The guests that fit the cavity best give the most stable compounds. In addition, in the case of a polar guest, hydrogen-bond formation frequently stabilizes the orientation as shown by crystal structures.

The observation of RTP in the different organized media needs to fulfil two main conditions. Firstly, the presence of heavy atoms, internal or external, in the environment of the potential phosphor is necessary to obtain RTP emission. In addition, phosphorescence is only obtainable if quenching of the emitting triplet-state, by small amounts of dissolved oxygen, is prevented.

The two conditions are common to micelles and cyclodextrins but, to obtain significant RTP emission in cyclodextrins, the hydrophobic $\mathrm{CD}$ cavities need to allow sufficient interaction between the analyte and the heavy atom compound to produce effective population of the triplet states of the analyte. For this, both the lumiphor and the heavy atom need to be in close proximity at the same time, i.e. inside the $\mathrm{CD}$ cavity [32].

\section{RTP from halogenated guest molecules}

The hydrophobic CD cavities need to allow sufficient interactions with the heavy atom compound to produce effective population of the triplet states of the sequestered analytes. In addition, the cavities must be sufficiently protective to the excited states of the occluded guest molecules that RTP can be generated.

In table I, the series of halogenated guest compounds that phosphoresce at room temperature when included in CDs have been summarized.

Turro et al. [33] were the first authors to report host-guest associations of different cationic surfactants with $\beta$ - and $\gamma$-CDs. No evidence for association could be detected for $\alpha$-CD. Phosphorescence measurements were made on solutions, which were purged 5-10 minutes with $\mathrm{N}_{2}$.

The phosphorescence of the 4-bromo-1-naphthoyl group is readily quenched by molecular oxygen in homogeneous solvents. However, when this lumiphore is complexed with $\gamma$-CD its phosphorescence is observed even under 1 atom of oxygen [34]. In the presence of $\alpha$ - and $\beta-C D$, oxygen quenches the phosphorescence, even though the compounds form complexes with $\beta-C D$.

Table I. Halogenated guest molecules showing RTP in CD solutions.

\begin{tabular}{lcc}
\hline Compound & CD used & Reference \\
\hline p-benzoyl [5-(4-bromo-1-naphthoyl)-1-pentyl]benzoate & $\gamma$-CD & 34 \\
1-bromo-5-(4-bromo-1-naphthoyl)pentane & $\gamma$-CD & 34 \\
[1-(4-bromo-1-naphthoyl)methyl]-trimethylammonium bromide & $\beta$ and $\gamma$-CD & 33 \\
[5-(4-bromo-1-naphthoyl)penthyl]-trimethylammonium bromide & $\beta$ and $\gamma$-CD & 33,34 \\
5-(4-bromo-1-naphthoyl)--1-pentanol & $\gamma$-CD & 34 \\
[10-(4-bromo-1-naphthoyl)decyl]-trimethylammonium bromide & $\beta$ and $\gamma$-CD & 33 \\
1-bromonaphthalene & $\beta$-CD and glucosyl modified $\beta-C D$ & $35-37,40,43-53,77,83$ \\
2-bromonaphthalene & $\beta$-CD & $36,38,39,83$ \\
4-bromobiphenyl & $\alpha-$, methyl $\beta$-CD and $\gamma$-CD & 63 \\
6-bromo-2-naphthol & $\alpha-C D$ & $58-60$ \\
bromocyclohexane & $\beta$-CD \\
1-chloronaphthalene & $\beta$-CD & 55 \\
2-chloronaphthalene & $\alpha$-CD & 35,54 \\
2-chloroquinoline & $\beta-C D$ & 61 \\
4-chloroquinoline & $\beta-C D$ & 56,57 \\
4-ethyl-4'-iodo(1,1'-biphenyl) & $\beta-C D$ & 56,57
\end{tabular}


Similarly, 1-bromo and 1-chloronaphthalene phosphorescing in nitrogen purged solutions containing $\beta$-CD were studied. Addition of acetonitrile enhances both the phosphorescence intensity and life-time, because of the formation of a complex composed of $\beta-\mathrm{CD}, 1$-halonaphthalene and one or more acetonitrile molecules, which fill the CD interior sufficiently enough to exclude quenchers, including oxygen [35]. Scypinski et al. [36] reported on RTP from 1-bromonaphthalene and 2-bromonaphthalene in $\beta$-CD solutions. Although the solutions show RTP in the absence of an external heavy atom, 1,2-dibromoethane was used to enhance RTP emission.

In all the above-mentioned studies, the procedure for deoxygenation of the solutions was consisting to purging with $\mathrm{N}_{2}$. Díaz García and Sanz-Medel [37] proposed the use of sodium sulfite for deoxygenation in RTP studies in fluid solution, both for micelles and for CDs. They reported on 1-bromonaphthalene RTP in $\beta$-CD in the presence of sodium sulfite.

RTP of 2-bromonaphthalene was also obtained in mixtures of SDS and $\beta-C D$. The solutions were deoxygenated by using $0.04 \mathrm{M}$ sodium sulfite [38]. Sodium bromide was used as external heavy atom to enhance the RTP signal.

Wei et al. [39] reported on RTP from 2-bromonaphthalene included in $\beta-\mathrm{CD}$, using $0.05 \mathrm{M} \mathrm{KI}$ or $7.5 \mathrm{mM} \mathrm{Tl}_{2} \mathrm{SO}_{4}$ as external heavy atoms, and sodium sulfite as deoxygenant. After 5 minutes (or 20 minutes for the $\mathrm{Tl}_{2} \mathrm{SO}_{4}$ system) the RTP was measured. The KI system was more sensitive, quicker and less susceptible to changes in cyclodextrin, heavy atom concentration and $\mathrm{pH}$ than the $\mathrm{Tl}_{2} \mathrm{SO}_{4}$ system. The calibration graph was rectilinear from 1 to $40 \mu \mathrm{M}$ 2-bromonaphthalene. The method was simpler than the method which used halide alkanes as a heavy atom source and $\mathrm{N}_{2}$ deoxygenation [36].

Intense phosphorescence was observed when alcohols of different sizes and lengths were introduced in aqueous solutions containing 1-bromonaphthalene and a glucosylmodified- $\beta$-cyclodextrin [40]. The association of the bromonaphthalene to the CD was increased in the presence of alcohols by formation of ternary complexes. This is similar to a previous report on ternary complex formation of pyrene included in $\beta$-CD [41] or $\gamma$-CD [42] in the presence of alcohols. The phosphorescence enhancement induced by alcohol is related to its effectiveness in shielding photoexcited 1-bromonaphthalene from oxygen. The rate constants for oxygen quenching decrease generally as the bulkiness of the alcohol increases. Tert-butyl alcohol and cyclohexanol give rise to the smallest oxygen quenching rate constants and the highest emission quantum yields. Deoxygenation of solutions is not necessary for the observation of the phosphorescence emission. Later on [43] the RTP of this system was enhanced by an external magnetic field.

Also in aerated $\beta-C D$ solutions, an intense RTP was observed from 1-bromonaphthalene in the presence of Triton $\mathrm{X}-100$ for surfactant concentrations below the CMC [44]. Triton X-100 is incorporated into the hydrophobic cavity of
$\beta-C D$ as the second guest molecule, and a 1:1:1 ternary complex is formed. The addition of ethanol further enhances the RTP of the ternary complex whereas 1-propanol and 1-butanol greatly attenuate RTP. Similarly, in the presence of cyclohexane the RTP from 1-bromonaphthalene in $\beta-C D$ is enhanced [45].

Other alcohols investigated were $n$-butanol, propan-2-ol, isoamylalcohol and cyclohexanol, in the presence of $\alpha-C D$, $\beta-C D, \gamma-C D$, methyl- $\beta-C D$, hydroxypropyl- $\beta-C D$ and malto- $\beta$-CD. Intense RTP signals from 1-bromonaphthalene were observed without deoxygenation [46]. Results suggest that the alcohol bonds to the rim of the cyclodextrin cavity via hydrogen bonding between their hydroxyl groups and the aliphatic chains of the alcohol cover the top and bottom of the cavity by hydrophobic interaction, shielding the lumiphore from oxygen and preventing RTP from quenching.

Du et al. [47] reported on the RTP of a complex of inclusion of $\beta$-CD:1-bromonaphthalene in the presence of naphthalene and 1-butanol. Naphthalene and 1-butanol are also included in the cyclodextrin cavity, enhancing the protection of the lumiphor against quenchers and, consequently, increasing RTP emission from the system.

A solution of sodium dodecylbenzenesulfonate was employed by the same group [48] to enhance the RTP signal from 1-bromonaphthalene. Similarly, [49] aliphatic alcohols (from ethanol to $n$-octanol) were studied as potentially enhancing molecules. The maximum signal was obtained with $n$-pentanol. The system $\beta$-CD:1-bromonaphthalene:tercbutanol was found to give an intense RTP emission without deoxygenation.

Intense RTP of 1-bromonaphthalene induced by anionic surfactants was studied in aerated aqueous $\beta$-CD solutions [50]. Analyses of spectral structure and surface tension of solutions, suggested that the hydrophobic hydrocarbon chain of surfactants was partly included in the apolar cavity of $\beta-C D$ and the part with the polar head group of hydrocarbon chain located outside the cavity, coiled over the top of $\beta-C D$, providing an effective protection for RTP. Since it contained a surfactant with a polar head group, the complex precipitation was homogeneously dispersed in aqueous solution and stable RTP was obtained.

As an alternative, Xie et al. [51] employed a series of surfactants as sodium dodecylsulfate, cetyltrimethylammonium bromide or chloride, Triton X-100 and Tween 20, to study the phosphorescence of 1-bromonaphthalene in $\beta$-CD solutions, without deoxygenation. Intense RTP signals were obtained in the cases of non ionic or anionic surfactants. However, for the cationic surfactants the RTP signal was very low. Du et al. [52] suggested that the presence of surfactants produces an effective protection of the triplet states of the analyte. Similarly, they employ p-t-octylpolyethylenglycol-phenyl-ether to enhance the RTP from 1-bromonaphthalene in $\beta-C D$ and proposed a determination method in the range $0-5 \mu \mathrm{g} \cdot \mathrm{mL}^{-1}$, reporting a LOD of 4 ng.mL $L^{-1}$ [53]. 
Hydrogen and $\mathrm{CO}_{2}$ generated respectively from the systems of solid $\mathrm{Zn} / \mathrm{HCl}$ and $\mathrm{Na}_{2} \mathrm{CO}_{3} / \mathrm{HCl}$ were also proposed for deoxygenation in RTP studies. The method was applied in the determination of 1-chloronaphthalene in $\beta-C D$ in the presence of 1,2-dibromoethane [54].

The RTP emission from bromocyclohexane in $\beta$-CD solutions in the presence of ethanol, methanol and tetrachloromethane was reported. The deoxygenation of the solutions is not necessary and the presence of turbidity is observed. The addition of benzene or bromobenzene did not produce such an effect [55].

Scypinski et al. [56] reported on the obtention of RTP emission of nitrogen heterocycles such as 2-chloroquinoline and 4-chloroquinoline. Although other reports of RTP of nitrogen heterocycles on solid surfaces have appeared, there has been little work on RTP of these molecules in fluid solution. Chloroquinolines exhibed weak emission of RTP in deoxygenated $\beta-C D$ which could be ascribed to the tripletstate induced from this internal atom effect. Upon addition of 1,2-dibromoethane (1,2-DBE) showed only RTP and no fluorescence. In CD/1,2-DBE solution, nitrogen heterocycles and bromoalkane are thought to form a trimolecular complex with the $\mathrm{CD}$, being partially immune to quenching by molecular oxygen.

Femia et al. [57] made use of synchronous wavelength scanning luminescence for the compared study of 2 and 4-chloroquinoline in cyclodextrin and micellar media. Synchronous wavelength scanning of the $\beta$-CD mixture required background substraction, which was a tedious process imposing constraints on the selectivity and sensitivity. However, synchronous wavelength scanning of the micellar mixture did not require background correction, which made micellar media to be superior to the cyclodextrin medium.

The complex of inclusion between $\alpha-\mathrm{CD}$ and 6-bromo-2naphthol in aerated aqueous solutions was found to present RTP emission [58]. The phosphorescence is due to the formation of a 1:2 (6-bromo-2-naphthol: $\alpha$-CD) complex [59]. Later on, Escandar et al. [60] studied the influence of different factors on the phosphorescence emission. The signal is enhanced by previous irradiation of the solutions with the xenon lamp of the spectrofluorimeter, and is 13 times more intense when the solutions are deoxygenated by $\mathrm{N}_{2}$ purging.

In the 2:1 $\alpha$-CD:2-chloronaphthalene complex, in the presence of D-glucose in aqueous solutions, the RTP of 2-chloronaphthlene was observed. The RTP emission was further enhanced in the presence of KI. Deoxygenation of the solutions was not necessary [61].

Zhu et al. [62] studied the effects of alcohols on RTP of $\beta$-CD:4-ethyl-4'-iodo-(1,1'-biphenyl):bromocyclohexane. The presence of a fourth component, the alcohol, enhanced the RTP intensity. This component acts as a lid for the CD cup because of the alcohol hydroxyl bonds to the rim of the CD by hydrogen-bonding and the alkyl end of alcohol flips over the two tops of the $\mathrm{CD}$ due to hydrophobic interaction forces. That is why the analyte is shielded from $\mathrm{O}_{2}$, decreasing the collision quenching of oxygen. Moreover, there is a decrease of the micropolarity of the CD cavity, and the formation constant of ternary inclusion complex increases.

The same authors [63] studied the CD induced RTP of 4bromobiphenyl without deoxygenation. Some cyclodextrin derivatives were tested including $\alpha-, \beta-$, methyl $\beta$ - and $\gamma-C D$, but the most effective was the last one. The $\gamma$-CD solution was mixed with acetonitrile, which provided the required solubilization of the $\mathrm{CD}$, giving a transparent solution.

\section{RTP from non-halogenated guest molecules}

In this case, the presence of heavy-atom species is necessary because the analytes do not contain halogen atoms in their structures. Such types of compounds are represented in table II.

In 1983, Cline Love and Weinberger [64] studied the phosphorescence characteristics of some polynuclear aromatic hydrocarbons (PAHs) including phenanthrene, naphthalene, 1-phenylnaphthalene and acenaphthene in the presence of $\beta-C D$ solutions and 1,2-DBE as the external heavy atom. Cyclodextrin selectivity based on size can be observed with a mixture of 1-phenylnaphthalene and naphthalene dissolved in $\beta$-CD and excess 1,2-DBE. Intense RTP was obtained for the smaller naphthalene, which fits neatly into the $\beta$ cavity, and no phosphorescence is detectable from the larger molecule. It should be noted that 1-phenylnaphthalene is phosphorescent and that this is a size exclusion effect. With regard to the oxygen quenching of phosphorescence, it was found, when studying the acenaphthene, that the aerated solutions presented RTP, but when using deaerated solutions the intensity was doubly increased.

Scypinski et al. [36] obtained RTP by the inclusion of some PAHs in cyclodextrins using 1,2-DBE as the external heavy atom. The phenomenon of cyclodextrin room temperature phosphorescence (CD-RTP) is highly selective according to molecular geometry of the lumiphor and cyclodextrin cavity. Besides, it is partially insensitive to oxygen interferences. From the studied PAHs, it was noticed that the phosphorescence of anthracene, fluoranthene and pyrene was higher in $\gamma$-CD than in $\beta$-CD. In the case of chrysene, phosphorescence was observed just with $\gamma$-CD solutions.

Two- and three-ring nitrogen heterocycles and the bridged biphenyl heterocycles were studied by Scypinski et al. [56]. The RTP was due to the formation of a trimolecular inclusion complex composed of lumiphor, cyclodextrin and an external heavy atom,1,2-DBE. Nitrogen heterocycles exhibit phosphorescence in $\beta-C D$ because of their unprotonated forms. Their CD-RTP is partially immune to quenching by molecular oxygen depending on the water solubility of the lumiphor. More water-soluble molecules exit from the CD cavity at a faster rate and they spend more time in the bulk 
Table II. Non-halogenated guest molecules showing RTP in CD solutions.

\begin{tabular}{|c|c|c|}
\hline Compound & $C D$ used & References \\
\hline acenaphthene & $\beta-C D$ and $\gamma-C D$ & $36,57,64,71-73,75,76,79,80,84$ \\
\hline acenaphthylene & $\beta-C D$ & 75,83 \\
\hline 1-naphthyacetic acid & $\beta-C D$ & $66-69$ \\
\hline 2-naphthyloxyacetic acid & $\beta-C D$ & $68-70$ \\
\hline acridine & $\beta-C D$ & 56,57 \\
\hline 1-aminoquinoline & $\beta-C D$ & 56 \\
\hline anthracene & $\beta-C D$ and $\gamma-C D$ & 36,57 \\
\hline 5,6-benzoquinoline & $\beta-C D$ & 56,57 \\
\hline 7,8-benzoquinoline & $\beta-C D$ & $56,75,76,83,84$ \\
\hline biphenyl & $\beta-C D$ & $36,56,57$ \\
\hline carbazole & $\beta-C D$ & $56,57,75$ \\
\hline chrysene & $\gamma-C D$ & 36,57 \\
\hline dibenzofuran & $\beta-C D$ & 56,57 \\
\hline dibenzothiophene & $\beta-C D$ & 56,57 \\
\hline 1,3-dimethylnaphthalene & $\beta-C D$ & 36 \\
\hline 1,4-dimetylnaphthalene & $\beta-C D$ & 36 \\
\hline fluoranthene & $\beta-C D$ and $\gamma-C D$ & $36,56,57$ \\
\hline fluorene & $\beta-C D$ & $36,56,76,83,84$ \\
\hline isoquinoline & $\beta-C D$ & $56,57,75$ \\
\hline lepidine & $\beta-C D$ & 56,57 \\
\hline 1-methylnaphthalene & $\beta-C D$ & 36 \\
\hline 2-methylnaphthalene & $\beta-C D$ & 36 \\
\hline 7-methylquinoline & $\beta-C D$ & $56,57,74,75,83$ \\
\hline naphthalene & $\beta-C D$ & $32,36,57,64,75$ \\
\hline 1-naphthylacetamide & $\beta-C D$ & 70 \\
\hline 1-naphthol & $\beta-C D$ & 36,81 \\
\hline 2-naphthol & $\beta-C D$ & 81 \\
\hline naproxen & $\beta-C D$ & 32 \\
\hline phenanthrene & $\beta-C D$ & $32,36,54,57,64,65,75-78,83,84$ \\
\hline phenanthridine & $\beta-C D$ & 56,57 \\
\hline 1,7-phenanthroline & $\beta-C D$ & 56,57 \\
\hline 1,10-phenanthroline & $\beta-C D$ & $40,56,57$ \\
\hline 4,7-phenanthroline & $\beta-C D$ & 56 \\
\hline phenazine & $\beta-C D$ & 56,57 \\
\hline 1-phenylnaphthalene & $\beta-C D$ & 64 \\
\hline pyrene & $\beta-C D$ and $\gamma-C D$ & $36,41,42,57,75$ \\
\hline quinazoline & $\beta-C D$ & 56 \\
\hline quinoline & $\beta-C D$ & $54,56,57,75,82$ \\
\hline $\mathrm{TNS}^{\star}$ & $\beta-C D$ & 38 \\
\hline triphenyle & $\beta-C D$ & 36 \\
\hline triphenylene & $\beta-C D$ & 57 \\
\hline
\end{tabular}

* 6-(p-toluidino)-2-naphthalenesulfonic acid potassium salt

solution where they are quenched more effectively. That is the reason why the less soluble molecules such as quinoline and phenazine show $<10 \%$ unquenched phosphorescence in the presence of oxygen, while the more soluble analytes such as 1,10-phenanthroline and acridine show little or no phosphorescence emission remaining after aeration. Bridged biphenyls, in which a five-member ring serves to induce planarity in the molecule, exhibit more intense CD-RTP than biphenyl. 
Cline Love and Grayeski [32] carried out some additional phosphorescence studies using deaerated solutions with high-purity nitrogen passed through oxygen trap sealed with a teflon stopper, in the presence of 1,2-DBE as the heavy atom. When using $\alpha-, \beta-$, and $\gamma-\mathrm{CD}$, it is observed again the size exclusion effect, which leads just the analytes included within the CD cavity, at least partially, to be induced to phosphoresce. Molecules too large to fit into the $\beta$-CD cavity (e.g., 1-phenylnaphthalene) will not emit, whereas naphthalene fits easily into the cavity and emits strongly. In order to explain the effect of cavity size, it was checked that phenanthrene phosphoresces in $\beta-C D$ but does not in the smaller $\alpha-C D$, which cannot include the molecule. On the other hand, the hydrophobicity of the compound establishes the strength of the complex, more hydrophilic species form weaker complexes producing faint emission signals. In this way, naproxen, a relatively non-polar drug, shows lower RTP intensity compared to that observed in micellar media, because of the weak inclusion in cyclodextrin.

A mixture of organized media consisting of cyclodextrin and SDS was also used to obtain RTP from phenanthrene [65]. It was studied the differences between the phosphorescence spectral profiles of phenanthrene in $\beta$-CD:1,2-DBE complex and in Na/TIDS (70:30) micellar solution. Besides, this work documents the effects of surfactant concentration both below and above the CMC, on the triplet state properties of the trimolecular complex. Surfactant concentrations well below the CMC produce an enhancement of phenanthrene's phosphorescence intensity, which is thought to be the result of sequestering of the open ends of the CD torus by hydrophobic tails of the surfactant monomers. Addition of more surfactant, above the CMC, caused migration of the lumiphor from the $\beta-\mathrm{CD}$ to the micellar aggregate. In this way, it was postulated that the surfactant monomers aggregate at the open ends of the $\beta$-CD torus, effectively "capping" the system and reducing the degree of lumiphor-water interaction.

Another study [57] was performed using the same compounds as the ones used by Scypinski [53] and some ones more, including naphthalene, triphenylene, phenenthrene, chrysene, fluorantane, anthracene and pyrene. Synchronous wavelength scanning was employed in order to compare the RTP signals of different compounds using micellar media or $\beta-C D$, in deaerated solutions. Such experiments were achieved using thallous nitrate and 1,2-DBE as heavy atoms. In both cases, second derivative synchronous spectra were performed to enhance the spectral resolution. It was noticed the appearance of turbidity due to the $\beta-\mathrm{CD}: 1,2-\mathrm{DBE}$ complex, which can be reduced by using lower concentration of 1,2-DBE, but with a concomitant reduction in RTP intensity. In the same way, micelle induced RTP was found to be better than cyclodextrin-induced RTP for the analysis of mixtures. In the case of the drugs, propanolol and its 4-hydroxy metabolite were resolved in micellar media; however, the drug did not exhibit RTP in $\beta$-CD. The surfactant medium offered several advantages over the $\mathrm{CD}$, particularly when analytes are too large to be included in the CD cavity. Also, micelles provide freedom from the spectral interference due to turbidity produced by the heavy-atom: $\beta-C D$ complex.

The determination of 1-naphthylacetic acid in $\beta$-CD solutions was reported by Zhang et al. using as heavy atoms 1,2-DBE [66] and 1,2-dibromopropane (1,2-DBP) [67]. In both cases the solutions were deaerated by passing $\mathrm{N}_{2}$.

2-Naphthyloxiacetic acid (NOA) and 1-naphthylacetic acid (NAA) were studied by Muñoz de la Peña et al. $[68,69]$ with stabilization by using $\beta-\mathrm{CD}$ as a host system. 2-bromoethanol and 2,3-dibromopropanol were evaluated as external heavy atom perturbers to enhance the rate of intersystem crossing and, consequently, populating the triplet state for phosphorescence emission. Sodium sulfite was used as chemical deoxygenant. Later on, the same authors [70] performed an experience with NOA in order to demonstrate that the emission intensity is much higher in the presence of bromoalkanes (1,3-bibromopropane) than in the presence of bromoalcohols. The solutions deoxygenation was achieved by a combination of flowing nitrogen and addition of sodium sulfite. It was also noticed a turbidity formed in the presence of the bromoalkane, which seems necessary to obtain phosphorescence.

The complex acenaphthene: $\beta-C D$ has been studied by several authors. The room temperature phophorescence [71] of acenaphthene was observed when using 2-bromoethanol as external heavy atom, thanks to the formation of the ternary complex acenaphthene: $\beta-C D: 2$-bromoethanol. The solutions were deaerated by nitrogen purging.

The same complex was studied by Muñoz de la Peña et al. [72]. The deaeration was made by using a chemical deoxygenant, sodium sulfite, in the same way as the procedure performed for obtaining RTP in micellar media [36], and the formation constant of the ternary associate was also determined.

Shuang et al. [73] compared the RTP signal of the complex acenaphthene: $\beta-C D$ in the presence of epibromohydrin as the atom perturber, as opposed to the one formed when using 1,2-DBE. It was found that the heavy atom effect of epibromohydrin was superior to that of 1,2-DBE.

Bromocyclohexane was used to replace straight chain alkane halides, such as 1,2-DBE and 1,2-DBP, as the heavy atom perturber for $\beta$-CD induced RTP of 7-methylquinoline, without nitrogen purging [74]. Linear ranges, detection limits and relative standard deviation were similar to those obtained for the system using 1,2-DBP and nitrogen purging.

It was observed RTP of some polyaromatic hydrocarbons and nitrogen heterocycles [75] included in the $\beta$-CD:cyclohexane:haloalkane system and using nitrogen purging as deoxygenant. The addition of an excess of 1,2-DBE caused "cloudy precipitations", which provided strong RTP signals. It was seen from microscopy that the precipitations suspended in solution were microcrystals of $\beta-C D$ and its inclusion components. The formation of microcrystals benefited the stability of the triplet-state and the enhancement effect 
on RTP. Therefore, in these systems, rigid processes might be completed in two steps: complexation and forming suspension microcrystals.

In 1996, Gao et al. [76] determined several PAHs by $\beta$-CD RTP with 1,2-DBE as heavy atom using the chemical deoxygenation technique. Results were comparable with those obtained by using $\mathrm{N}_{2}$ deoxygenation.

Using chloroform as external heavy atom, Nazarov [77] studied the phosphorescence of phenanthrene in $\beta$-CD solutions.

The traditional deoxygenation techniques in $\mathrm{CD}$ induced RTP, including nitrogen purging and chemical deoxygenation by using sodium sulfite, were compared to the new techniques proposed by Zhang et al. [78]. Phenanthrene was studied in $\beta$-CD solutions with 1-bromocyclohexane as perturber. The authors concluded that the methods in which oxygen was eliminated by hydrogen gas and carbon dioxide in the measuring media (new techniques) are easy to use; do not need any complicated supplementary equipment; are rapid because deoxygenation time needed was only 1-2 min; have a wider acidic condition which is a supplement of chemical deoxygenation by sodium sulfite; can maintain RTP signal without decay for 10 minutes and finally, have good analytical characteristics.

Carretero et al. [79] carried out a multivariate optimization approach, using a central composite blocked cube-star design, to optimize the RTP of a ternary complex between acenaphthene: $\beta$-CD:bromoalcohol, two alcohols, including 2-bromoethanol and 2,3-dibromopropanol being studied. The comparative study of the effect of both of them in the phosphorescent response showed that the highest emission signal was obtained with 2,3-dibromopropanol. The same experience was performed by Escandar and Muñoz de la Peña [80] with the difference that they used $\gamma-\mathrm{CD}$, with comparable results.

The effect of small molecule organic compounds including methanol, ethanol, propan-1-ol, propan-2-ol, butan-1-ol, ethylene glycol, acetonitrile, acetone and 2-butanone on RTP of two ternary complexes of $\beta$-CD:analyte:1,2-DBE was investigated by Zhang [81]. The studied analytes were 1 and 2-naphthol. Nitrogen purging was used to eliminate the dissolved oxygen.

Quinoline was determined in $\beta-C D$ solutions and in the presence of 1,2-BDE as the heavy atom. The elimination of dissolved oxygen was performed by chemical deoxygenation [82].

Bai et al. [83] carried out the determination of a mixture of seven polycyclic aromatic hydrocarbons which was treated with epibromohydrin in $\beta$-CD solutions. Sodium sulfite was added to remove the $\mathrm{O}_{2}$.

Gao et al. [84] studied four of the previous compounds in the same conditions except that the external heavy atom was 2-bromoethanol.
Table III. Halogenated cyclodextrin derivatives inducing RTP from several included analytes.

\begin{tabular}{llc}
\hline Compound & \multicolumn{1}{c}{$C D$ used } & Reference \\
\hline $\begin{array}{l}\text { acenaphthene } \\
\text { dibenzofuran } \\
\text { dibenzothiophene } \\
\text { fluorene }\end{array}$ & heptakis(6-bromo-6-deoxi- $\beta$-CD) & 85 \\
$\begin{array}{l}\text { naphthalene } \\
\text { phenanthrene } \\
\text { pyrene }\end{array}$ & \\
$\begin{array}{l}\text { 2-cloronaphthalene } \\
\text { 6-bromo-2-naphtol }\end{array}$ & 6-deoxi-6-iodo- $\beta$-CD & 86 \\
3-bromoquinoline & & 87 \\
naphthalene & 6-deoxi-6-iodo- $\beta-C D$ & 88 \\
\end{tabular}

\section{RTP from halogenated cyclodextrin derivatives}

"Functionalization" of CDs by including heavy atoms in its molecular structures allows the observation of phosphorescence of several compounds. The cyclodextrins modified and the compounds included into them are summarized in table III.

The "heavy atom" serves to enhance the radiative rate of triplets without a comparable enhancement of triplet quenching. The result is an enhanced quantum yield of phosphorescence.

Femia and Cline Love [85] were the first in using a modified cyclodextrin, heptakis(6-bromo-6-deoxi- $\beta$-CD), in order to obtain RTP from several polynuclear aromatic hydrocarbons, such as acenaphthene, dibenzofuran, dibenzothiophene, fluorene, naphthalene, phenanthrene and pyrene (with no heavy atoms in their structures). Appreciable phosphorescence only occurs when the lumiphor is shielded from quenchers by the cyclodextrin torus and are within the realm of influence of heavy atoms. By locking the heavy atom into a fixed position on the $\mathrm{CD}$ molecule, the observed phosphorescence and dynamic interactions depend primarily on the entrance and exit rate constants of the lumiphor from the CD. The samples were shaken vigorously, causing the solution to become cloudy as the inclusion complex forms. They were also deaerated 15 min with $\mathrm{N}_{2}$. It was made clear that the heavy atom effect is capable of exerting its influence either through attachment of bromine to the fixed carbon skeleton of the $\beta-\mathrm{CD}$ complexed to a lumiphor or from the close approach of the lumiphor to the bromo-substituted, narrow end of the cyclodextrin. 
Some years later, Hamai et al. dealt with another kind of modifications on the cyclodextrins, investigating 6-deoxi-6iodo- $\alpha-C D(\alpha-C D I)$ and 6-deoxi-6-iodo- $\beta-C D(\beta-C D I)$. The author reported that, in aqueous solution, $\beta$-CDI formed a $1: 1$ inclusion complex with 2-chloronaphthalene (2-CN) [86]. Although $\beta-\mathrm{CD}$ also induces the RTP of $2-\mathrm{CN}$ on formation of an inclusion complex with this compound, $\beta$-CDI, containing a heavy atom perturber in its structure, is more than 1.2 times as effective in enhancing the RTP than $\beta$-CD.

Later on [87] the external heavy atom effect of $\alpha$-CDI on the RTP intensity of 6-bromo-2-naphthol and 3-bromoquinoline inclusion complexes was also examined. The RTP for the 2:1 $\alpha$-CDI: compound inclusion complex was compared with the 2:1 inclusion complex composed of the parent $\alpha-C D$, indicating the enhancement of the signal, due to the external heavy atom of the cyclodextrin. Finally, the same author [88] studied the luminescent behaviour of naphthalene in aqueous solutions of D-glucose using $\beta$-CDI.

\section{Acknowledgements}

The authors gratefully acknowledge the DGESIC (Project PB98-099) and the Consejeria de Educacion y Tecnologia de la Junta de Extremadura (Projet IPR99C034) for financially supporting this work.

\section{References}

1. Muñoz de la Peña, A.; Ndou, T. T.; Warner I. M. Spectroscopic studies in organized media. An overview, in Advances in Multidimensional Luminescence; Warner, I. M.; McGown, L. B. (Eds), Greenwich: JAI Press, Vol. II., 1993.

2. Kalyanasundaram, K.; Grieser, F.; Thomas, K. K. Chem. Phys. Lett. 1977, 51, 501

3. Cline Love, L. J.; Skrilec, M.; Habarta, J. G. Anal. Chem. 1980, 52, 754.

4. Skrilec, M.; Cline Love, L. J. J. Phys. Chem. 1981, 85, 2047.

5. Muñoz de la Peña, A.; Espinosa Mansilla, A.; Murillo Pulgarín, J. A.; Alañón Molina, A.; Fernández López, P. Analyst 1998, 123, 2285.

6. Muñoz de la Peña, A.; Espinosa Mansilla, A.; Murillo Pulgarín, J. A.; Alañón Molina, A.; Fernández López P. Talanta 1999, 48, 1061.

7. Sanz-Medel, A.; Martínez García, P. L.; Díaz García, M. E. Anal. Chem. 1987, 59, 774.

8. Fernández de la Campa, M. R.; Díaz García, M. E.; SanzMedel, A. Anal. Chim. Acta. 1988, 212, 235.

9. Liu, Y.-M.; Fernández de la Campa, M. R.; Díaz García, M. E.; Sanz-Medel, A. Anal. Chim. Acta 1990, 234, 233.

10. Segura Carretero, A.; Cruces Blanco, C.; Fernández Gutiérrez, A. Talanta 1996, 43, 1001.

11. Ramis Ramos, G.; Khasawneh, I. M.; García-Álvarez-Coque, M. C.; Winefordner, J. D. Talanta 1988, 35, 41.

12. Jin, W.-J.; Wei, Y.-S.; Duan, W.-S.; Liu, C.-S. Anal. Chim. Acta 1994, 287, 95.

13. Cruces Blanco, C.; Segura Carretero, A.; Fernández Gutiérrez, A. Anal. Chim. Acta 1996, 318, 357.
14. Segura Carretero, A.; Cruces Blanco, C.; Fernández Gutiérrez, A. Analyst 1997, 122, 925.

15. Muñoz de la Peña, A.; Anigbogu, V.; Ndou, T. T.; Warner, I. M. Anal. Chem. 1991, 63, 1018.

16. Schuette, J. M.; Ndou, T. T.; Muñoz de la Peña, A.; Greene, K. L.; Willianson, C. K.; Warner, I. M. J. Phys. Chem. 1991, 95, 4897.

17. Smith, V. K.; Ndou, T. T.; Muñoz de la Peña, A.; Warner, I. M. J. Inclus. Phenom. 1991, 10, 471.

18. Anigbogu, V.; Muñoz de la Peña, A.; Ndou, T. T.; Warner, I. M. Anal. Chem. 1992, 64, 484.

19. Anigbogu, V.; Muñoz de la Peña, A.; Ndou, T. T.; Warner, I. M. J. Chrom. 1992, 594, 37.

20. Hysain, N.; Ndou, T. T.; Muñoz de la Peña, A.; Warner, I. M. Appl. Spec. 1992, 46, 652.

21. Schuette, J. M.; Ndou, T. T.; Muñoz de la Peña, A.; Mukundan Jr., S.; Warner, I. M. J. Am. Chem. Soc. 1993, 115, 292.

22. Will, A. Y.; Muñoz de la Peña, A.; Ndou, T. T.; Warner, I. M. Appl. Spec. 1993, 47, 277.

23. Durán-Merás, I.; Muñoz de la Peña, A.; Salinas, F.; Rodríguez Cáceres, M. I. Analyst 1994, 119, 1215

24. Muñoz de la Peña, A.; Salinas, F.; Durán-Merás, I.; Moreno, M. D. Anal. Letters 1994, 27, 1893.

25. Aaron, J.-J.; Laasis, B.; Mahedero, M. C.; Muñoz de la Peña, A.; Salinas, F. J. Inclus. Phenom. \& Mol. Recog. Chem. 1994, $18,69$.

26. Will, A. Y.; Muñoz de la Peña, A.; Ndou, T. T.; Warner, I. M. Appl. Spec. 1995, 49, 520.

27. Maafi, M.; Laasis, B.; Aaron, J.-J.; Mahedero, M.; Muñoz de la Peña, A.; Salinas, F. J. Inclus. Phenom. \& Mol. Recog. Chem. 1995, 22, 235.

28. Maafi, M.; Laasis, B.; Aaron, J.-J.; Mahedero, M.; Muñoz de la Peña, A.; Salinas, F. J. of Fluorescence 1997, 7, $25 \mathrm{~S}$.

29. Muñoz de la Peña, A.; Agbaria, R. A.; Sánchez Peña, M.; Warner, I. M. Appl. Spec. 1997, 51, 153.

30. Durán-Merás, I.; Muñoz de la Peña, A.; Salinas, F.; Rodríguez Cáceres, M. I. Appl. Spec. 1997, 51, 684.

31. Muñoz de la Peña, A.; Ndou, T.; Zung, J. B.; Warner, I. M. J. Phys. Chem. 1991, 95, 3330.

32. Cline Love, L. J.; Grayeski, M. L.; Norski, J.; Weinberger, R. Anal. Chim. Acta 1985, 170, 3.

33. Turro, N. J.; Okubo, T.; Chung, C. J. J. Am. Chem. Soc. 1982, 104, 1789 .

34. Turro, N. J.; Cox, G. S.; Li, X. Photochem. Photobiol. 1983, $37,149$.

35. Turro, N. J.; Bolt, J. D.; Kuroda, Y.; Tabushi, I. Photochem. Photobiol. 1982, 35, 69.

36. Scypinski, S.; Cline Love, L. J. Anal. Chem. 1984, 56, 322.

37. Díaz García, M. E.; Sanz-Mendel, A. Anal. Chem. 1986, 58 , 1436.

38. Kim, H.; Crouch, S. R. Anal. Chem. 1989, 61, 2475.

39. Wei, Y.; Liu, C.; Zhang, S. Fenxi Huaxue 1990, 18, 1001.

40. Ponce, A.; Wong, P. A.; Way, J. J.; Nocera, D. G. J. Phys. Chem. 1993, 97, 1137.

41. Muñoz de la Peña, A.; Ndou, T. T.; Zung, J. B.; Greene, K. L.; Live, D. H.; Warner, I. M. J. Am. Chem. Soc. 1991, 113, 1572.

42. Zung, J. B.; Muñoz de la Peña, A.; Ndou, T. T.; Warner, I. M. J. Phys. Chem. 1991, 95, 6701. 
43. Zhang, Y.; Huang, X.; Xu, J. Gaodeng Xuexiao Huaxue Xиebao 1994, 15, 181.

44. Du, X. Z.; Zhang, Y.; Huang, X. Z.; Jiang, Y. B.; Li, Y.-Q.; Chen, G.-Z. Appl. Spectrosc. 1996, 50, 1273.

45. Xie, J.; Xu, J.; Chen, G.; Liu, Ch. Sci. China Ser. B: Chem. 1996, 39, 416.

46. Zhao, Y.; Li, L.; Tong, A. Fenxi Huaxue 1997, 25, 1016.

47. Du, X. Z.; Zhang, Y.; Huang, X.-Z.; Li, Y. Q.; Jiang, Y. B.; Chen, G. Z. Spectrochim. Acta 1996, 52A, 1541.

48. Du, X. Z.; Zhang, Y.; Huang, X. Z.; Jiang, Y. B.; Chen, G. Z. Spectrochim. Acta 1996, 53A, 671.

49. Du, X. Z.; Zhang, Y.; Jiang, Y. B.; Lin, L. R.; Huang, X. Z.; Chen, G. Z. Gaodeng Xиехiao Huахие Хиеbao 1997, 18, 1935.

50. Du, X. Z.; Zhang, Y.; Jiang, Y. B.; Lin, L. R.; Huang, X. Z.; Chen, G. Z. Ниахие Хиеbаo 1998, 56, 453.

51. Xie, J.; Huang, D.; Xu, J.; Chen, G. Chin. Sci. Bull. 1997, 42, 1468.

52. Du, X. Z.; Jiang, Y. B.; Huang, X. Z.; Chen, G. Z. Chin. Chem. Lett. 1997, 8, 431.

53. Du, X. Z.; Zhang, Y.; Jiang, Y. B.; Lin, L. R.; Huang, X. Z.; Chen, G. Z. Talanta 1997, 44, 511.

54. Zhang, H. R.; Wei, Y. S.; Jin, W. J. Fenxi Huaxue 1996, 24, 1253.

55. Chen, Y. L.; Li, L. D. Fenxi Huaxue 1995, 23, 264.

56. Scypinski, S.; Cline Love, L. J. Anal. Chem. 1984, 56, 331.

57. Femia, R. A.; Cline Love, L. J. Spectrochim. Acta 1986, 42A, 1239.

58. Hamai, S. J. Chem. Soc. 1994, Chem. Commun. 2243.

59. Hamai, S. J. Phys. Chem. 1995, 99, 12109.

60. Muñoz de la Peña, A.; Pérez Rodríguez, M.; Escandar, G. M. Talanta 2000, 51, 949.

61. Hamai, S. J. Phys. Chem. 1997, B, 101, 1707.

62. Zhu, Y.; Li, L.; Tong, A. Guangpuxue Yu Guangpu Fenxi 1998, $18,617$.

63. Zhu, Y. P.; Li, L. D.; Tong, A. J. Fenxi-Shiyanshi 1998, 17, 6.

64. Cline Love, L. J.; Weinberger, R. Spectrochim. Acta 1983, $38 B, 1421$.

65. Femia, R. A.; Cline Love, L. J. J. Coll. Interf. Sci. 1985, 108, 271.
66. Zhang, S.; Liu, C.; Bu, Y. Fenxi Huaxue 1988, 16, 494.

67. Zhang S, Liu C, Bu Y, Fenxi Huaxue 1988, 16, 682.

68. Muñoz de la Peña, A.; Salinas, F.; Acedo, M. I.; Gómez, M. J.; Sánchez Peña, M. J. Inclus. Phenom. \& Molec. Recog. Chem. 1993, 15, 131.

69. Muñoz de la Peña, A.; Salinas, F.; Gómez, M. J.; Sánchez Peña, M.; Durán-Merás, I. Talanta 1993, 40, 1657.

70. Muñoz de la Peña, A.; Mahedero, M. C.; Espinosa Mansilla, A.; Bautista Sánchez, A.; Reta, M. Talanta 1999, 48, 15

71. Hamai, S. J. Am. Chem. Soc. 1989, 111, 3954.

72. Muñoz de la Peña, A.; Durán Meras, I.; Salinas, F.; Warner, I. M.; Ndou, T. T. Anal. Chim. Acta 1991, 255, 351.

73. Shuang, S.; Liu, C.; Feng, K.; Zhang, S. Fenxi Huaxue 1991, 19, 1265.

74. Wei, Y.; Liu, C.; Zhang, S. Fenxi Huaxue 1991, 19, 533.

75. Jin, W.; Wei, Y.; Xu, A.; Liu, C. Spectrochim. Acta 1994, 50A, 1769.

76. Gao, C. G.; Wei, Y. S.; Jin, W. J.; Liu, C. S. Fenxi Huaxue 1996, 24, 1015

77. Nazarov, V. B.; Gerko, V. I.; Alfimov, M. V. Izv. Akad.: Nauk. Ser. Khim. 1996, 4, 1014.

78. Zhang, H. R.; Zhang, J.; Wei, Y. S.; Jin, W. J.; Liu, C. S. Anal. Chim. Acta 1997, 357, 119.

79. Carretero, A. S.; Blanco, C. C.; Gutierrez, A. F.; Muñoz de la Peña, A. Appl. Spectrosc. 1998, 52, 420.

80. Escandar, G. M.; Muñoz de la Peña, A. Anal. Chim. Acta 1998, 370, 1999.

81. Zhang, H. R.; Wei, Y. S.; Wu, F.; Liu, C. S., Fenxi-Huaxue 1998, 26, 77.

82. Wang, Q.; Li, L. D.; Tong, A. Fenxi-Huaxue 1998, 26, 271.

83. Bai, X. H.; Wei, Y. S.; Liu, C. S. Fenxi-Huaxue 1998, 26, 243.

84. Gao, C. G.; Wei, Y. S.; Jin, W. J.; Liu, C. S. Fenxi-KexueХиebao 1998, 14, 292.

85. Femia, R. A.; Cline Love, L. J. J. Phys. Chem. 1985, 89, 1897.

86. Hamai, S.; Mononobe, N. J. Photochem. Photobiol. 1995, A 91, 217.

87. Hamai, S.; Kudou, T. J. Photochem. Photobiol. 1998, A 113, 135 .

88. Hamai, S. Bull. Chem. Soc. Jpn 1998, 71, 1549. 